\title{
Biotransformation of food spice curcumin by gut bacterium Bacillus megaterium DCMB-002 and its pharmacological implications
}

\author{
Chun-Yan $\mathrm{An}^{\mathrm{a}, \mathrm{b} *}$, Zhen-Zhen Sun ${ }^{\mathrm{b} *}$, Liang Shen ${ }^{\mathrm{a}, \mathrm{b}}$ and Hong-Fang $\mathrm{Ji}^{\mathrm{a}, \mathrm{b}}$

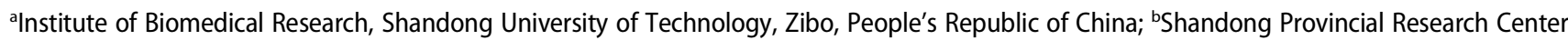 \\ for Bioinformatic Engineering and Technique, School of Life Sciences, Shandong University of Technology, Zibo, People's Republic of China
}

ABSTRACT

The food additive curcumin shows many benefits for human health but has low solubility and stability, which leads to its low bioavailability. After oral administration, curcumin undergoes biotransformation by gut microbiota in digestive tracts, and thus it is interesting to characterize the biotransformation products of curcumin and assess their bioactivities to help us understand the pharmacology. Herein a bacterial strain of Bacillus megaterium DCMB-002 isolated from mice feces, showed the capability of transforming curcumin to its various derivatives. The tracing high performance liquid chromatogram coupled with quadrupole time-of-flight tandem mass spectra (HPLC-Q-TOF MS ${ }^{n}$ ) led to the identification of seven hydrogenation transformation metabolites through reduction, hydroxylation, demethylation and demethoxylation etc, six of which were reported for the first time. The metabolites exhibited moderate antioxidant activity. The findings provided insights into the microbial biotransformation of curcumin and roles of gut microbiota in its pharmacological effects.
ARTICLE HISTORY

Received 17 August 2017

Accepted 29 November 2017

\section{KEYWORDS}

Curcumin; Bacillus

megaterium;

biotransformation;

HPLC-Q-TOF; antioxidant

\section{Introduction}

Curcumin (CUR), the main active constituent of a traditionally used food additive, spice and herbal medicine Curcuma longa L., is a polyphenolic molecule possessing various bioactivities, such as antioxidant, anticancer, anti-inflammatory and anti-microbial activities etc [1-3]. However, CUR has very low bioavailability owing to its poor water solubility and structural stability, which is contradictory to the diversity of its pharmacological activities [4-6]. Based on this, a hypothesis was raised that the degradation or biotransformation products of CUR may make important contributions to its diverse bioactivities $[5,7,8]$. One of the supporting evidences was that the detected concentration of parent CUR molecule in human circulatory system was much lower than that in human intestinal tracts $[9,10]$. Additionally, many CUR analogues were also found in human or rat hepatocytes, plasma, and brain, indicative of some CUR structural transformation while assimilated from gut to blood $[11,12]$.

The ability of gut microbiota to biotransform CUR has been reported by several studies [13-17]. In the present study, the biotransformation of CUR by a strain of bacterium Bacillus megaterium DCMB-002 isolated from fresh feces of mice under aerobic condition, was investigated. The metabolites of CUR transformed by the bacterium was illustrated using tracing high performance liquid chromatogram coupled with quadrupole time-of-flight tandem mass spectra (HPLC-Q-TOF $\mathrm{MS}^{\mathrm{n}}$ ), and the DPPH radical-scavenging ability of the transformation metabolites mixture was evaluated. Seven metabolites (M1 M7), inclusive products of reduction, hydroxylation, methylation and demethylation/demethoxylation of CUR, were identified, and the transformation metabolites mixture exhibited moderate antioxidant activity. This study is meaningful to interpret the role of the single bacterium in intestinal microorganism-mediate biotransformation of CUR.

\section{Material and methods}

\section{Chemicals and instruments}

Curcumin (99\%), butylated hydroxytoluene (BHT), gallic acid (GA), $\alpha, \alpha$-diphenyl- $\beta$-picrylhydrazyl (DPPH) and ascorbic acid (VC) were obtained from Sigma-Aldrich Shanghai Trading Co. (Shanghai, China); HPLC grade

CONTACT Hong-Fang Ji jhf@sdut.edu.cn; Liang Shen shen@sdut.edu.cn E Institute of Biomedical Research, Shandong University of Technology, Zibo, Shandong, People's Republic of China; Shandong Provincial Research Center for Bioinformatic Engineering and Technique, School of Life Sciences, Shandong University of Technology, Zibo, Shandong, People's Republic of China

*Contribute equally to the work.

(-) Supplementary data can be accessed here.

( 2017 The Author(s). Published by Informa UK Limited, trading as Taylor \& Francis Group.

This is an Open Access article distributed under the terms of the Creative Commons Attribution License (http://creativecommons.org/licenses/by/4.0/), which permits unrestricted use, distribution, and reproduction in any medium, provided the original work is properly cited. 
acetonitrile were purchased from Thermo Fisher Scientific technology Co. (Shanghai, China); ethyl acetate (EtOAc), isopropanol (iPrOH), 1-butanol (nBuOH), ethyl and methyl alcohol were from Sinopharm Chemical Reagent Co. Ltd. (Shanghai, China). All other reagents were of analytical grade.

Termovap sample concentrator (MD200-2) was purchased from Hangzhou Allsheng Instrument Co., Ltd (Hangzhou, China). Microplate reader (Multiskan GO 1510) was purchased from Thermo Fisher Scientific Oy (Ratastie 2, FI-01620 Vantaa, Finland).

\section{Bacteria isolation and identification}

The bacterium DCMB-002 was isolated from fresh feces of 7-months aged healthy mice. Aimed to enrich the bacteria who could utilize and transform the CUR molecule, an enrichment medium (FC) containing CUR as the sole carbon source was used to isolate and screen gut bacteria from fresh healthy mice feces. The $\mathrm{FC}$ medium contains CUR $50 \mathrm{mM},\left(\mathrm{NH}_{4}\right)_{2} \mathrm{SO}_{4} 2.0 \mathrm{~g} / \mathrm{L}, \mathrm{KH}_{2} \mathrm{PO}_{4} 1.0 \mathrm{~g} /$ $\mathrm{L}, \mathrm{K}_{2} \mathrm{HPO}_{4} 1.0 \mathrm{~g} / \mathrm{L}, \mathrm{MgSO}_{4} \bullet 7 \mathrm{H}_{2} \mathrm{O} 0.4 \mathrm{~g} / \mathrm{L}$ and deionized water with natural $\mathrm{pH}$ value. Firstly, $1.0 \mathrm{~g}$ of fresh mice feces were collected in a sterile Eppendorf tube, triturated and put into $\mathrm{FC}$ medium ( $50 \mathrm{~mL}$ in a $250 \mathrm{~mL}$ flask). After cultured for 2 to 3 days in shaker incubator at $37^{\circ} \mathrm{C}$ and $200 \mathrm{rpm}, 5.0 \mathrm{~mL}$ cultured solution was transformed to another FC medium same as above. After three times repeated culture, $100 \mu \mathrm{L}$ of the cultured solution was coated onto FC plates (with $20 \mathrm{~g} / \mathrm{L}$ agar) equably, and the plates was incubated at $37^{\circ} \mathrm{C}$ for $12-16 \mathrm{~h}$. The colonies grew on new respective plates until pure clones were obtained (Fig. S1).

The identification of the isolated bacteria was performed using a molecular biological protocol by DNA amplification and sequencing of the $16 \mathrm{~S}$ rDNA as described previously [18]. The resulting sequence data obtained from the bacterium strain has been deposited at GenBank (with accession number MF159101). The result from the BLAST search indicated that the sequence was the same (with the identity of $100 \%$ ) as that for the sequence of $B$. megaterium (compared with the B. megaterium strain 39-Y94, KU647232). The strain is preserved at School of Life Sciences, Shandong University of Technology (SDUT).

\section{Biotransformation of CUR by the bacterium DCMB- 002}

The bacterium strain DMCB-002 was cultured in liquid Lurina-Bertani (LB) medium (peptone $10 \mathrm{~g} / \mathrm{L}$, yeast extract $5 \mathrm{~g} / \mathrm{L}, \mathrm{NaCl} 10 \mathrm{~g} / \mathrm{L}, \mathrm{H}_{2} \mathrm{O}, \mathrm{pH}$ 7.0) for $12 \mathrm{~h}$ until the value of $\mathrm{OD}_{600}$ (optical density, $600 \mathrm{~nm}$ ) was 1.6. Then, $30 \mu \mathrm{L}$ of bacterial culture and CUR stock solution $(2.0 \mathrm{mM}, \mathrm{MeOH})$ was added into LB liquid medium, with the final concentration of CUR of $50 \mu \mathrm{M}$ and the final volume of $3.0 \mathrm{~mL}$. Triplicate cultures were prepared in parallel. In addition, two controls were used, one without bacterium strain and one without CUR. The batches were incubated at $37^{\circ} \mathrm{C}$ for $48 \mathrm{~h}$ with stirring at $200 \mathrm{rpm}$. Samples $(500 \mu \mathrm{L})$ were collected at $0,8,24$, and $48 \mathrm{~h}$, and bacterial cells were removed by centrifugation for $10 \mathrm{~min}$ at $5000 \mathrm{rpm}$. The supernatant was collected and extracted with $500 \mu \mathrm{L}$ solvents (EtOAc: $\mathrm{PrOH}: \mathrm{nBuOH}=90: 5: 5, v / v / v$ ) for 3 times. The extracts were combined and dried under $\mathrm{N}_{2}$ at $37^{\circ} \mathrm{C}$. The samples were filtrated with $0.22 \mu \mathrm{m}$ microfiltration membrane for HPLC analysis. The samples of metabolites for bioactivity tests were prepared in a larger scale of $150 \mathrm{~mL}$ in a $500 \mathrm{~mL}$ flask.

\section{HPLC and MS conditions}

HPLC analysis for bacterial metabolites was performed on an Agilent 1260 infinity (USA) HPLC System equipped with a G1311B quaternary pump, a G1329B automated sample injector, a G1315D UV-DAD detector, and a Thermo Hypersil GOLD C18 column $(4.6 \mathrm{~mm} \times$ $250 \mathrm{~mm}, 5 \mu \mathrm{m})$. With the injection volume of $20.0 \mu \mathrm{L}$, samples were eluted by a linear gradient mobile phase consisted by solvent A ( $\mathrm{ACN}, 0.1 \%$ formic acid) and $\mathrm{B}$ $\left(\mathrm{H}_{2} \mathrm{O}, 0.1 \%\right.$ formic acid $)$ at a flow rate of $1.0 \mathrm{~mL} / \mathrm{min}$. The gradient procedure was as follows, $0-7 \mathrm{~min}, 5 \% \mathrm{~A}$; 7 - $57 \mathrm{~min}, 5 \%$ to $90 \% \mathrm{~A} ; 57-63 \mathrm{~min}, 90 \%$ to $100 \% \mathrm{~A} ; 63-$ $66 \mathrm{~min}, 100 \% \mathrm{~A} ; 66-70 \mathrm{~min}, 100 \%$ to $5 \% \mathrm{~A} ; 70-80 \mathrm{~min}$, $5 \%$ A. Samples were detected at the wavelength of 220,254 , 280 and $430 \mathrm{~nm}$.

The Agilent 6540 Ultra High Definition (UHD) accurate-mass Quadrupole Time-of-Flight (Q-TOF) LC/MS ${ }^{\mathrm{n}}$ systems (Agilent, USA) were used for mass spectrometer analysis. Chromatography was performed on the HPLC with a Unitary C18 column $(3 \mathrm{~mm} \times$ $100 \mathrm{~mm}, 5 \mu \mathrm{m}$ particle size). The mobile phase consisted of $0.1 \%$ formic acid in water (solvent A) and acetonitrile (solvent $\mathrm{B}$ ), and a gradient elution of 0-10 min, $0-8 \% \mathrm{~B} ; 10-40 \min , 8-45 \% \mathrm{~B} ; 40-$ $50 \mathrm{~min}, 45-95 \% \mathrm{~B} ; 50-60 \mathrm{~min}, 95 \% \mathrm{~B}$, was used for the equilibration of the column. The flow rate was $0.3 \mathrm{~mL} / \mathrm{min}$ and the injection volume was $3 \mu \mathrm{L}$. Q-TOF used dual-ESI as ion source interface and the ESI source was operated in the positive ionization mode. The scan range was from $\mathrm{m} / \mathrm{z} 100$ to 1700 . Other conditions were optimized as follows: drying gas flow rate, $8 \mathrm{~L} / \mathrm{min}$; gas temperature, $350^{\circ} \mathrm{C}$; nebulizer gas pressure, $35 \mathrm{psi}$; and capillary and fragmentor potentials, 3500 and $175 \mathrm{~V}$, respectively. The standard sample generated an $[\mathrm{M}+\mathrm{H}]^{+}$ion $(\mathrm{m} / \mathrm{z}$ 922.0117) to 
ensure accuracy during the MS analysis. The whole system was controlled by Agilent Qualitative Analysis B.04.01 software.

\section{Measurement of transformation rate}

The concentrations of residual CUR in medium with or without bacteria were measured and calculated by the calibration standard at the range of $0.05 \sim 50 \mu \mathrm{g} /$ $\mathrm{mL}$ of CUR (with a purity over 99\%) as $y=161.01$ $x+12.115,(x=$ CUR concentration, $y=$ average peak area), $R^{2}=0.9999$. The transformation rate was obtained as follows. CUR transformation rate (incu-

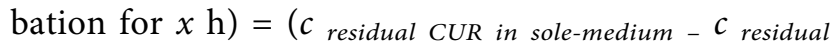
CUR in bacterial culture $) / C$ residual CUR in sole-medium $\times 100 \%$.

\section{Antioxidant assay for DPPH radical-scavenging activity}

The DPPH radical-scavenging activities of the samples were performed and modified according to the method of the previous report [19]. Briefly, all samples were resolved in HPLC grade $\mathrm{MeOH}$, except for VC in distilled water. A $100 \mu \mathrm{L}$ aliquot of test sample and $100 \mu \mathrm{L}$ aliquot of DPPH $(0.16 \mathrm{mM}, \mathrm{MeOH})$ was added into a 96-well microtitre plate as the sample group. Similar operations were performed for the sample blank group (samples added with $\mathrm{MeOH}$ ), the control group (DPPH added with $\mathrm{MeOH}$ or distilled water), and the blank group ( $\mathrm{MeOH}$ added with $\mathrm{MeOH}$ or distilled water) to eliminate the absorbance inferences from samples, DPPH solution and solvents. All mixtures were shanked and incubated in dark at room temperature $\left(32^{\circ} \mathrm{C}\right)$ for $30 \mathrm{~min}$, and then recorded the absorbance values at $517 \mathrm{~nm}$ by a microplate reader. The ability to scavenge the DPPH radical was calculated as follows. Scavenging rate $(\%)=\left[1-\left(A_{\text {sample }}-A_{\text {sample }}\right.\right.$ blank $\left.) /\left(A_{\text {control }}-A_{\text {blank }}\right)\right] \times 100 \%$. Each group was

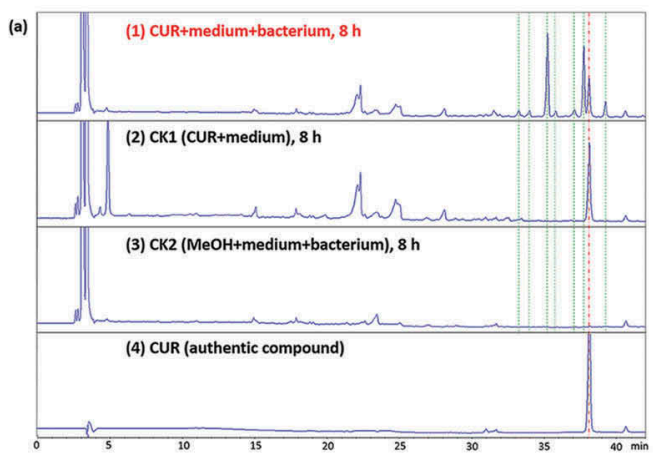

performed in triplicate. Synthetic antioxidants BHT, GA and $\mathrm{VC}$ were used as positive controls.

\section{Statistical analysis}

Values expressed are means of triplicate determinations \pm standard deviation. All statistical analyses were carried out using SPSS 16.0 for Windows.

\section{Results}

\section{Biotransformation of CUR}

In our previous research, the mice feces flora cultured under aerobic conditions showed capacity to biotransform CUR (paper not published). To illustrate the role of some important intestinal bacteria on CUR metabolism, the isolation, identification, and transformation screening of eight strains of aerobic/facultative bacteria from healthy mice feces were performed. As a result, a bacterium strain B. megaterium DCMB-002, was found to possess the ability to transform CUR significantly. HPLC was used to trace metabolites. Excluding the auto-degradation of CUR in the bacterium cultural medium and the bacterium self-metabolites during its lifecycle, seven metabolites (seen the peaks marked by green dashed lines in Figure 1(a-1)) transformed from CUR by the bacterium strain were detected after incubated at $37^{\circ} \mathrm{C}$ for $8 \mathrm{~h}$. Additionally, metabolites from CUR produced by the bacterium after 24 and $48 \mathrm{~h}$ culture were also detected (Figure 1(b)). Interestingly, some metabolites, such as the two peaks at retention time of 35.2 and $37.7 \mathrm{~min}$ in $8 \mathrm{~h}$ culture broth, disappeared at 24 or $48 \mathrm{~h}$, which suggested that the activities and categories of the transformation enzymes of the bacterium DCMB-002 differed in the stages of cell growth, and the two metabolites may act as middle products of moving-forward metabolism.

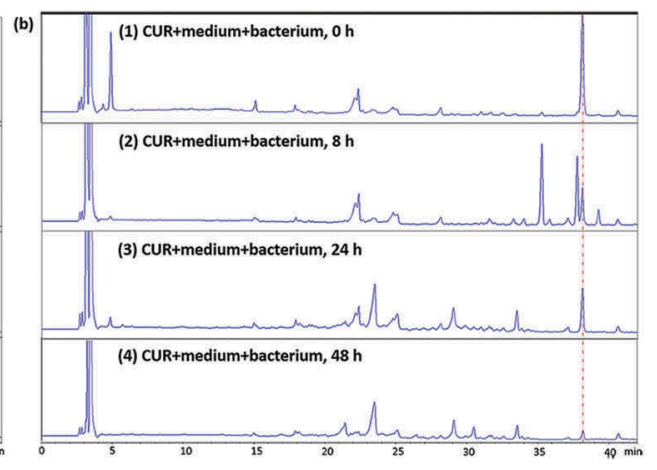

Figure 1. HPLC profiles (detected at $254 \mathrm{~nm}$ ) of metabolites produced by the bacterium strain DCMB-002. (a-1) Bacterial metabolites by mixing $50 \mu \mathrm{M}$ CUR, bacterium strain DCMB-002, and culture medium for $8 \mathrm{~h}$ incubation; (a-2) products of CUR after being incubated for $8 \mathrm{~h}$ in sole medium; (a-3) bacterial metabolites by adding equal volume of $\mathrm{MeOH}$ and incubating for $8 \mathrm{~h}$; (a-4) the authentic compound of CUR. (b) Metabolites of the bacterium with CUR added and incubated for $0,8,24$ and $48 \mathrm{~h}$. 
With the same initial concentrations of $50 \mu \mathrm{M}$ (i.e. $18.4 \mu \mathrm{g} / \mathrm{mL}$ ), the concentrations of CUR in bacterium culture decreased more rapidly than that in sole medium without bacteria (Figure 2(a)), which suggested CUR was consumed by the bacterium DCMB-002 apart from autodegradation (e.g. autoxidation) in medium. As time prolongs, the biotransformation rate of CUR by the bacterium increased from $42.0 \pm 2.35 \%$ ( 8 h-incubation) to $56.29 \pm 1.08 \%$ ( 24 h-incubation) and $75.86 \pm 0.13 \%$ (48 h-incubation), respectively (Figure 2(b)). However, HPLC traces exhibited that the variety of biotransformation metabolites obtained from $48 \mathrm{~h}$-incubation bacterial culture (especially at the retention time of $35.0 \sim 40 \mathrm{~min}$ ) was less abundant than that in 8 and 24 h-incubation bacterial cultures (Figure 1(b)), which seemed contrary to the trends of transformation rates. HPLC detection at other wavelength (220, 280 and $430 \mathrm{~nm}$ ) showed similar results (data not shown). A reasonable explanation was that with the maturing of the bacterial population, the CUR metabolites produced at early stages were further converted, like glycosylation and sulfation etc. The latterly produced more aqueously-soluble metabolites were not extracted by the lipophilic solvent with low polarity (EtOAc: iPrOH: $\mathrm{nBuOH}=90: 5: 5, v / v / v$ ) and retained in water cultures.

\section{Antioxidant activity of transformed metabolites extracts}

The antioxidant activity for DPPH radical-scavenging ability of the extracted mixtures after incubation was evaluated. As shown in Figure 3(a), the parent drug CUR has a similar DPPH radical-scavenging activity $(\mathrm{IC} 50=2.02 \pm 0.41 \mu \mathrm{g} / \mathrm{mL})$ to those of positive controls GA and BHT, yet better than that of L-ascorbic acid (VC). The bacterial co-cultured metabolites extracts, inclusive of both CUR biotransformation products, and residual CUR, CUR auto-degradation products and bacterial self-metabolites, showed DPPH radical-scavenging activity. This activity was enhanced with incubation time longer, with IC50 values of $5.57 \pm 0.07(8 \mathrm{~h})$ to $1.19 \pm 0.11(48 \mathrm{~h}) \mathrm{mg} / \mathrm{mL}$, which

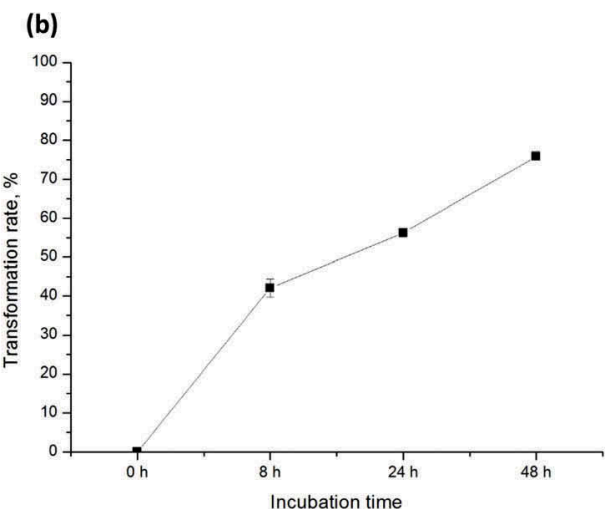

Figure 2. CUR residual concentrations (a) and biotransformation rates of CUR by the bacterium strain B. megaterium DCMB-002 (b).

(a)

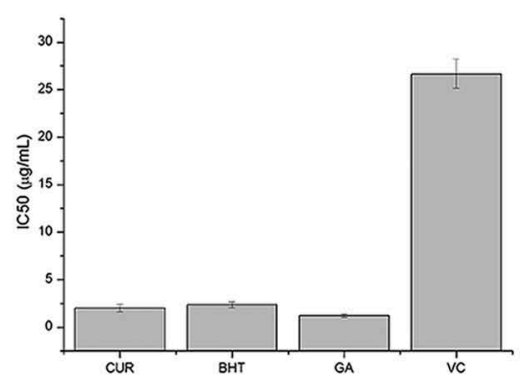

(b)

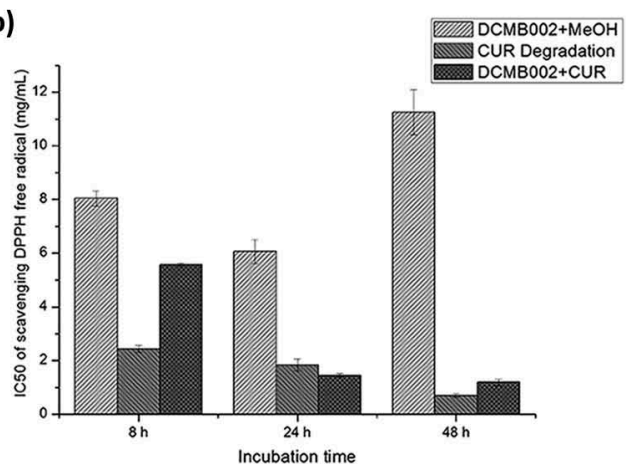

Figure 3. DPPH radical-scavenging activities of positive controls (a), and the extracts from cultures of 8,24 and $48 \mathrm{~h}$ incubation, including the bacterial self-metabolites, CUR auto-degradation products, and co-cultural products of mixing CUR and the bacterium, respectively (b). 
exhibited same trends as that of CUR auto-degradation products mixtures (Figure 3(b)). Especially, CUR biotransformation products incubated for $24 \mathrm{~h}$ showed stronger ability than 24 h-incubating CUR auto-degradation products (Figure 3(b)). The self-metabolites of the bacterium strain DCMB-002 exhibited weak antioxidant activity.

\section{Identification of CUR metabolites by B. megaterium DCMB-002}

To specify the CUR metabolites transformed by the bacterium DCMB-002, HPLC-Q-TOF MS $^{2}$ spectra was used to provide molecular weight and fragmentation information, data seen in Figure 4 and Table 1. Seven compounds were identified and six of them (except M3) are reported for the first time (Figure 5).

The parent compound CUR (M0) appeared in the bacterial culture of 8,24 , and $48 \mathrm{~h}$ incubation (Figure 4), who was eluted at a retention time of $34.57 \mathrm{~min}$. HRESIMS gave it an $[\mathrm{M}+\mathrm{H}]^{+}$ion at $\mathrm{m} / \mathrm{z}$ 369.1332 (see Supplementary data Fig. S2), appropriate for the molecular formula $\mathrm{C}_{21} \mathrm{H}_{21} \mathrm{O}_{6}$ (calcd 369.1333).

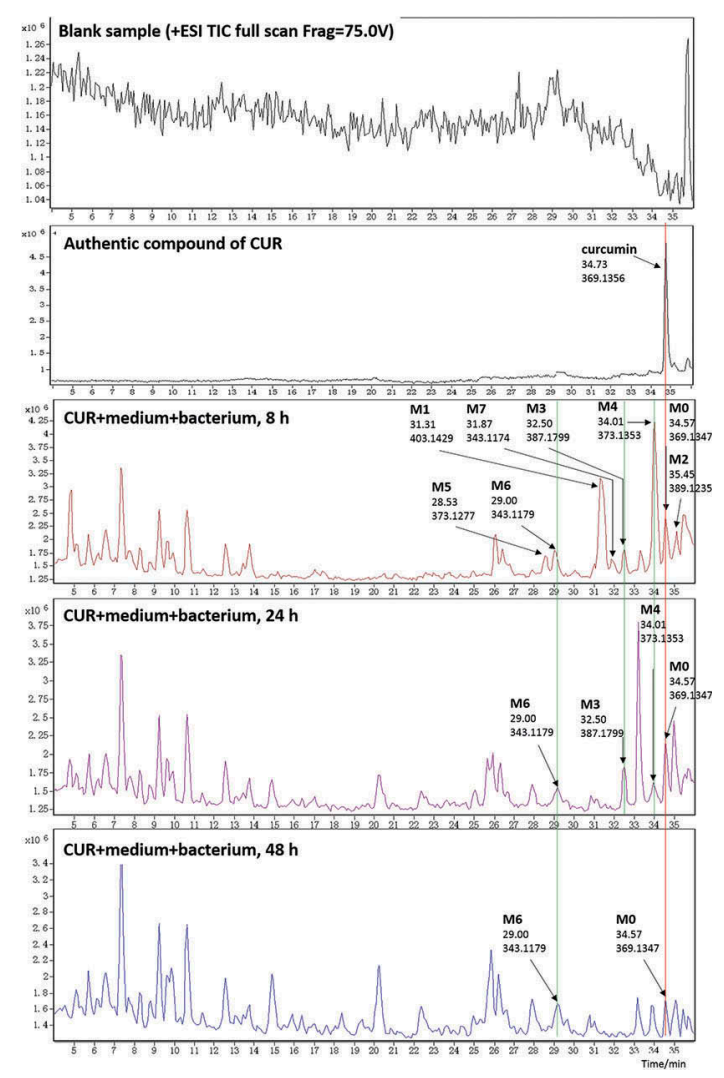

Figure 4. Total ion current chromatograms of the bacterial metabolites with incubation for 8,24 and 48 h. (red line: peak of CUR; green lines: common peaks of CUR metabolites in the three samples.).
Secondary mass spectra of M0 gave the fragmentation ions of $\mathrm{m} / \mathrm{z} 177,145,117,137$ and 161, same with those of authentic CUR (Fig. S3).

Compound M1 was obtained from the bacterial culture of $8 \mathrm{~h}$ incubation (Figure 4). It appeared in HPLC profile at a retention time of $31.31 \mathrm{~min}$, and contained a protonated molecular ion at $\mathrm{m} / \mathrm{z}$ 403.1429 (Fig. S4), which suggested a molecular formula $\mathrm{C}_{21} \mathrm{H}_{23} \mathrm{O}_{8}$ (calcd 403.1487), and $34 \mathrm{Da}$ higher than the protonated ion of CUR. This indicated that the compound M1 was hydroxylation and hydrogenation by adding two oxygen atoms and two hydrogen atoms. Moreover, the high collision energy scan fragment ions of $\mathbf{M 1}$ at $\mathrm{m} / \mathrm{z} 373$ and 327 were observed. The fragment ion at $\mathrm{m} / \mathrm{z} 373$ was generated by the loss of $\mathrm{OCH}_{2}(30 \mathrm{Da})$ from the parent ion. Then another loss of $\mathrm{OCH}_{2}(30 \mathrm{Da})$ and an oxygen atom from phenolic hydroxyl group (16 Da) formed the fragment ion of $\mathrm{m} / \mathrm{z} 327$ (Figure 6). M1 was tentatively identified as bis-hydroxylated dihydrocurcumin, while the location of the two hydroxy moieties can't be confirmed here.

Compound M2 was only detected from the metabolites of $8 \mathrm{~h}$ incubation (Figure 4). It was eluted at a retention time of $35.45 \mathrm{~min}$, and was assigned a molecular formula $\mathrm{C}_{20} \mathrm{H}_{20} \mathrm{O}_{8}$ based on its protonated iron of $\mathrm{m} / \mathrm{z} 389.1235$ (calcd for $\mathrm{C}_{20} \mathrm{H}_{21} \mathrm{O}_{8}, 389.1231$ ) by HRESIMS. The molecular weight of M2 was $14 \mathrm{Da}$ less than that of $\mathbf{M 1}$, suggesting a $\mathrm{CH}_{2}$ loss in the structure of M1. Moreover, $\mathrm{MS}^{2}$ spectra gave the fragment ions as seen in Table 1, which included a same ion of $\mathrm{m} / \mathrm{z}$ 327, a $14 \mathrm{Da}$ less ion of $\mathrm{m} / \mathrm{z} 359$ than ion of $\mathrm{m} / \mathrm{z} 373$ from M1, and $\mathrm{m} / \mathrm{z} 341$ (14 Da less than $\mathrm{m} / \mathrm{z}$ 355 produce by losing $\mathrm{H}_{2} \mathrm{O}$ from the ion at $\mathrm{m} / \mathrm{z} 373$ ) (Table 1 and Fig. S5). Thus, M2 was considered as a demethylated product of $\mathbf{M 1}$, and tentatively identified as bis-hydroxylated demethyl dihydrocurcumin.

Compound M3 was obtained from the bacterial culture extract of 8 and $24 \mathrm{~h}$ incubation. With a retention time of $32.50 \mathrm{~min}$ in TIC chromatogram, M3 was given a $[\mathrm{M}+\mathrm{H}]^{+}$ion of $\mathrm{m} / \mathrm{z} 387.1799$ by HRESIMS (Fig. S6), indicating a molecular formula $\mathrm{C}_{22} \mathrm{H}_{27} \mathrm{O}_{6}$ (calcd 387.1802). Since the M.W. of M3 was $18 \mathrm{Da}$ more than that of M0 and possessed one more carbon atom (12 Da), M3 was speculated having one more $\mathrm{CH}_{2}(14 \mathrm{Da})$ and $4 \mathrm{H}(4 \mathrm{Da})$ than M0. According to the metabolites of CUR reported, $\mathrm{CH}_{2}$ was hypothetically located on benzene ring and $4 \mathrm{H}$ on the two alkene bones of seven-carbon heptadione chain of CUR [15]. The observed high collision energy scan fragment ions of $\mathbf{M} 3$ at $\mathrm{m} / \mathrm{z} 105,121,69$ and 93 supported this speculation, because this result indicated the easier fragility of the linking chain between 
Table 1. Identification of CUR metabolites by HPLC-Q-TOF mass spectrometry.

\begin{tabular}{|c|c|c|c|c|c|}
\hline Metabolites & Sources culture & Retention time (min) & $\begin{array}{c}\text { Exact mass } \\
{[\mathrm{M}+\mathrm{H}]^{+}(\mathrm{m} / \mathrm{z})}\end{array}$ & Measured formula (error, ppm) & Fragment ions \\
\hline M0 & $8 h, 24 h, 48 h$ & 34.57 & 369.1332 & $\mathrm{C}_{21} \mathrm{H}_{21} \mathrm{O}_{6}(0.29)$ & $177,145,117,137,161,89$ \\
\hline M1 & $8 \mathrm{~h}$ & 31.31 & 403.1429 & $\mathrm{C}_{21} \mathrm{H}_{23} \mathrm{O}_{8}(-0.06)$ & 373,327 \\
\hline M2 & $8 \mathrm{~h}$ & 35.45 & 389.1235 & $\mathrm{C}_{20} \mathrm{H}_{21} \mathrm{O}_{8}(-1.08)$ & $359,341,327$ \\
\hline M3 & $8 \mathrm{~h}, 24 \mathrm{~h}$ & 32.50 & 387.1799 & $\mathrm{C}_{22} \mathrm{H}_{27} \mathrm{O}_{6}(0.89)$ & $105,121,69,93$ \\
\hline M4 & $8 \mathrm{~h}, 24 \mathrm{~h}$ & 34.01 & 373.1353 & $\mathrm{C}_{20} \mathrm{H}_{21} \mathrm{O}_{7}(-0.06)$ & $343,325,297$ \\
\hline M5 & $8 \mathrm{~h}$ & 28.53 & 373.1277 & $\mathrm{C}_{20} \mathrm{H}_{21} \mathrm{O}_{7}$ (1.3) & $343,329,357,315,339,137$ \\
\hline M6 & $8 \mathrm{~h}, 24 \mathrm{~h}, 48 \mathrm{~h}$ & 29.00 & 343.1179 & $\mathrm{C}_{19} \mathrm{H}_{19} \mathrm{O}_{6}(-0.89)$ & $313,285,181,59$ \\
\hline M7 & $8 \mathrm{~h}$ & 31.87 & 343.1174 & $\mathrm{C}_{19} \mathrm{H}_{19} \mathrm{O}_{6}(0.72)$ & $313,281,299,327,59$ \\
\hline
\end{tabular}

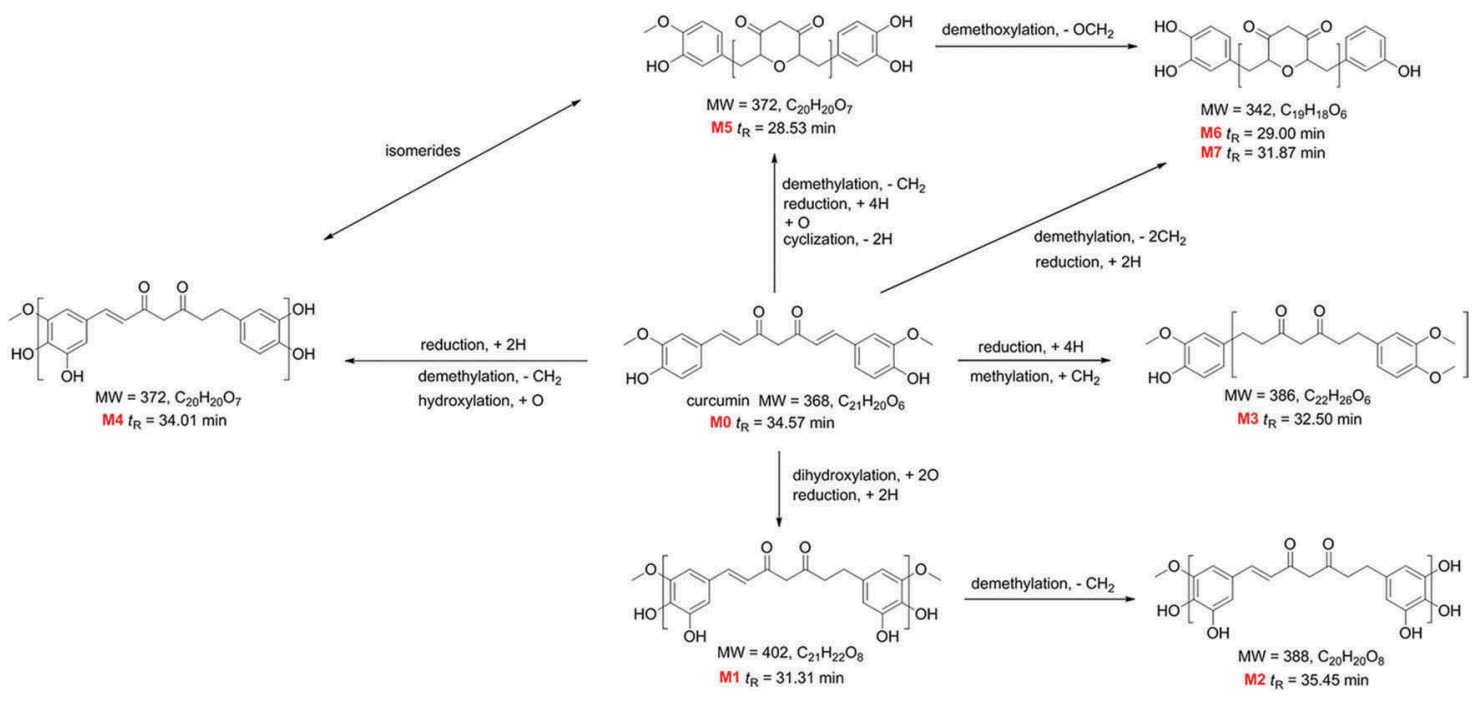

Figure 5. Metabolites of CUR transformed by intestinal bacterium B. megaterium DCMB-002.

aromatic rings after the saturation of two alkene bones by four hydrogen atoms. The $[\mathrm{M}+\mathrm{H}]^{+}$ion of $\mathrm{m} / \mathrm{z} 387$ lost a $\mathrm{H}_{2} \mathrm{O}(18 \mathrm{Da})$ to obtain an ion of $\mathrm{m} / \mathrm{z} 369$ $\left(\mathrm{C}_{22} \mathrm{H}_{25} \mathrm{O}_{5}\right)$, which produced the fragment ion of $\mathrm{m} / \mathrm{z}$ 69 by losing a neutral fragment of $\mathrm{C}_{18} \mathrm{H}_{20} \mathrm{O}_{4}(300 \mathrm{Da})$, and the fragment ion of $\mathrm{m} / \mathrm{z} 121$ by loss of $\mathrm{OCH}_{2}$ $(30 \mathrm{Da})$ and $\mathrm{C}_{13} \mathrm{H}_{14} \mathrm{O}_{3}(218 \mathrm{Da})$. The fragment ions of $\mathrm{m} / \mathrm{z} 107$ and 93 was obtained by the loss of one and two $\mathrm{CH}_{2}(14$ and $28 \mathrm{Da})$ from the ion of $\mathrm{m} / \mathrm{z} 121$, respectively. The rearrangement of p-hydroxybenzyl ion $(\mathrm{m} / \mathrm{z}$ 107) led to the loss of $2 \mathrm{H}(2 \mathrm{Da})$ and obtain the fragment ion of $\mathrm{m} / \mathrm{z} 105$ (Figure 6). Thus, M3 was identified as methylated tetrahydrocurcumin.

Compounds M4 and M5, with retention time of 34.01 and $28.53 \mathrm{~min}$, were given protonated ions of 373.1353 and 373.1277 , respectively, which were appropriate to the same ionic formula $\mathrm{C}_{20} \mathrm{H}_{21} \mathrm{O}_{7}$ (cald 373.1295), a carbon atom (12 Da) less than CUR, probably from the methoxyl moiety at benzyl ring. The same ionic formula proved that they are isomerides, but the obviously disparate retention times indicated they made a difference in hydrophobicity owing to their largely different structures. Considering $4 \mathrm{Da}$ more than M.W. of CUR, M4/M5 were speculated to get from loss of a $\mathrm{CH}_{2}(14 \mathrm{Da})$, together with addition of an $\mathrm{O}$ atom $(16 \mathrm{Da})$ and two hydrogen atoms $(2 \mathrm{Da})$. The following secondary fragmentation support this speculation. The high collision energy scan fragment ions of M4 were observed at $\mathrm{m} / \mathrm{z}$ 343, 325 and 297 (Table 1 and Fig. S7). The fragment ion of $\mathrm{m} / \mathrm{z} 343$ was $30 \mathrm{Da}$ less than the parent ion, suggesting an $\mathrm{OCH}_{2}$ (30 Da) loss from protonated ion of M4. Further, the ion of $\mathrm{m} / \mathrm{z} 343$ lost a $\mathrm{H}_{2} \mathrm{O}(18 \mathrm{Da})$ to generate the ion of $\mathrm{m} / \mathrm{z} 325$, and the latter ion lost a CO $(28 \mathrm{Da})$ to obtain the ion of $\mathrm{m} / \mathrm{z} 297$ (Figure 6). Compound M4 was tentatively identified as hydroxylated and demethylated dihydrocurcumin, but the position of hydroxylation and hydrogenation could not be characterized.

Based on the four hydrogen atoms adding to the double bones and demethylation of CUR, compound M5 was speculated to possessing a 3,5-tetrahydropyrandione moiety owing to the cyclization and addition of one oxygen atom. The speculation was supported by analysis of fragment ions. The secondary mass spectra showed the fragment ions of $\mathrm{m} / \mathrm{z} 343,329,357,315,339$ 

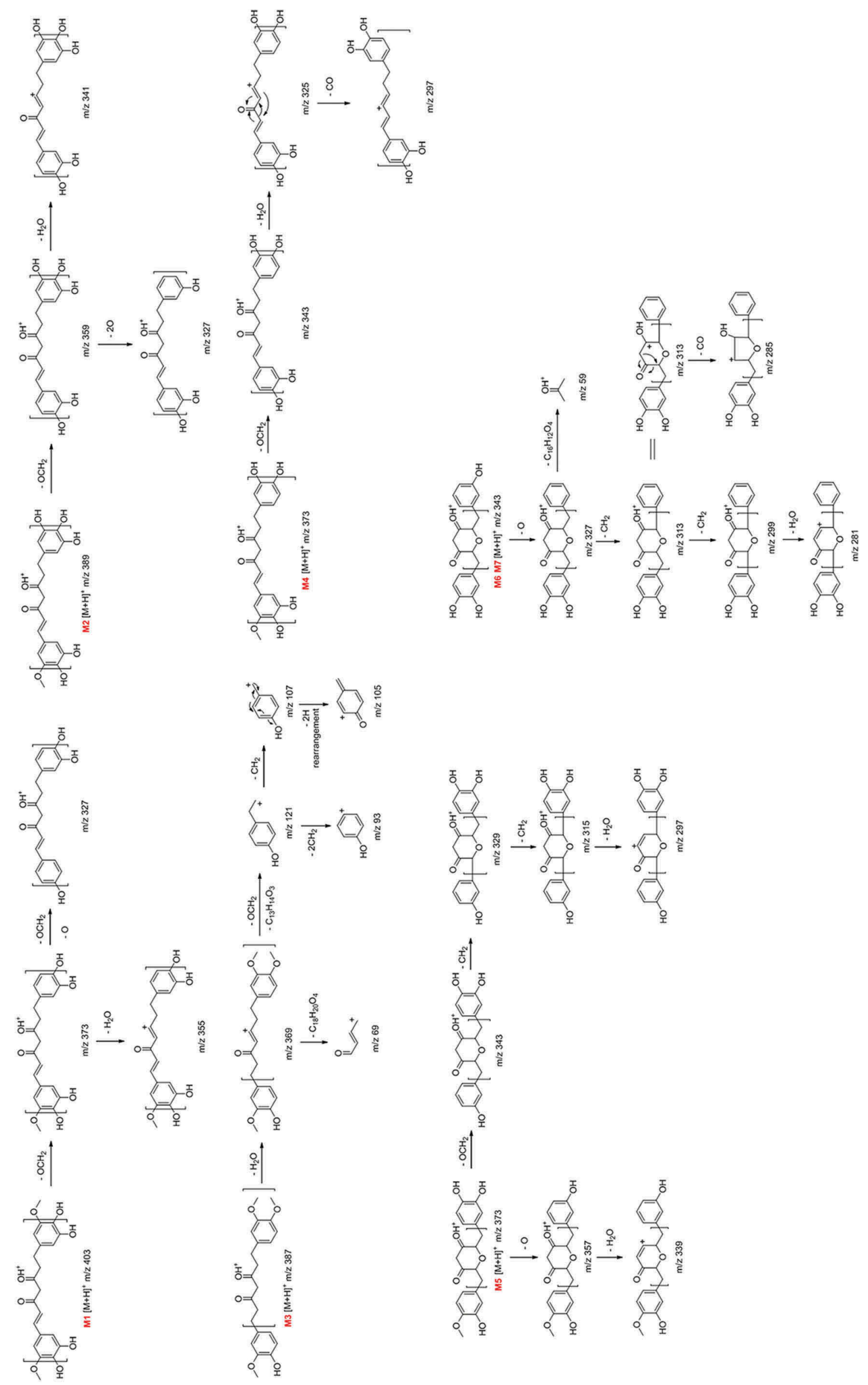
and 137, significantly different to those of M4 (Table and Fig. S8). The parent ion $\mathrm{m} / \mathrm{z} 373$ lost an $\mathrm{OCH}_{2}(30 \mathrm{Da})$ to form the ion $\mathrm{m} / \mathrm{z}$ of 343 , who successively lost two $\mathrm{CH}_{2}$ fragments (14 and $28 \mathrm{Da}$ ) and one $\mathrm{H}_{2} \mathrm{O}(18 \mathrm{Da})$ to obtain the fragment ions of $\mathrm{m} / \mathrm{z} 329$, 315 and 297. Meanwhile, the protonated M5 ion at $\mathrm{m} / \mathrm{z}$ 373 lost an oxygen atom (16 Da) to get the ion of $\mathrm{m} / \mathrm{z}$ 357 , which further lost a $\mathrm{H}_{2} \mathrm{O}(18 \mathrm{Da})$ to get the ion of $\mathrm{m} / \mathrm{z}$ 339. Compound M5 was identified as a 3,5-tetrahydropyrandione derive. M4 was detected from the culture extracts of 8 and $24 \mathrm{~h}$ incubation, and M5 was only found in the culture of $8 \mathrm{~h}$ incubation (Figure 4).

Compounds M6 and M7 $\left([\mathrm{M}+\mathrm{H}]^{+} 343.1179\right.$ and 343.1174 , respectively) are also a pair of isomeride with a ionic formula of $\mathrm{C}_{19} \mathrm{H}_{19} \mathrm{O}_{6}$ (cald 343.1176), and were eluted at retention times of 29.00 and $31.87 \mathrm{~min}$ (Figure 4). The M.W. of M6 and M7 were $30 \mathrm{Da}$ lower than $\mathrm{m} / \mathrm{z} 373$, which indicated a loss of $\mathrm{OCH}_{2}$ moiety from M4 or M5. However, because the retention time of M6 and M7 were between that of M5 $\left(t_{\mathrm{R}}=28.53 \mathrm{~min}\right)$ and $\mathbf{M} 4\left(t_{\mathrm{R}}=34.01 \mathrm{~min}\right)$ which indicates intervenient hydrophily, and the supporting $\mathrm{MS}^{2}$ fragmentation ions (seen in Table 1) were significant different with those of M4/M5, the skeletons of M6 and M7 were hard to be characterize. In our trials of speculating the parent ions' fragmentation pathway, the sharing carbon skeleton with M4 was found to be relatively reasonable for the $\mathrm{MS}^{2}$ fragmentation ions. The parent ion of $\mathrm{m} / \mathrm{z} 343$ lost an oxygen atom (16 Da) probably from benzyl ring to get the fragment ion of $\mathrm{m} / \mathrm{z}$ of 327 , who continued losing one or two $\mathrm{CH}_{2}$ (14 or $28 \mathrm{Da}$ ) to obtain the ions of $\mathrm{m} / \mathrm{z} 313$ and 299 . The fragment ion of $\mathrm{m} / \mathrm{z} 281$ was derived from $\mathrm{m} / \mathrm{z} 299$ by losing a $\mathrm{H}_{2} \mathrm{O}(18 \mathrm{Da})$. Another fragmentation pathway of $\mathrm{m} / \mathrm{z} 313$ was the loss of a CO $(28 \mathrm{Da})$ to get the ion of $\mathrm{m} / \mathrm{z}$ 285. M6 and M7 were also derived from 3,5tetrahydropyrandiones, but the positions of hydroxyl moieties could not be defined. M6 was found in the bacterial culture extracts of 8,24 and $48 \mathrm{~h}$ incubation, while $\mathbf{M} 7$ was only in the extract of $8 \mathrm{~h}$ (Figure 4).

\section{Discussion}

The low water-solubility is disadvantage for clinical application of CUR, while the low stability makes the essence of its pharmacological effects confused. When CUR passed though intestinal tract, CUR molecules interact with gut microorganism which leads the transformation of CUR to its analogues. Many researches showed that CUR transformed to kinds of its analogues including reduction of double bonds, demethylation and demethoxylation etc, which was ascribed to the bio-transformative roles of intestinal microorganism exclusive of organic enzymes [20-24]. In this work, an aerobic bacterium strain B. megaterium DCMB-002 was isolated from mice fresh feces and co-cultured with CUR. The strain of B. megaterium has been found as an important bio-tool bacterium with wide application in food and medicine industry and agriculture [25-30]. It has exhibited biotransformation function by modifying natural products to obtain more active derives, such as converting betulin to betulinic acid with anti-HIV and antitumor activities, and bio-transforming ursolic acid to its derives with nitric oxide production inhibitory activity $[26,29]$. Herein seven compounds from them were identified by LC/(+)ESI-MS/MS analysis, among which transformation forms, inclusive of reduction of heptadione chain (adding 2 or 4 hydrogen atoms) and hydroxylation/demethylation/ demethoxylation of aromatic rings, were speculated. In the assessment of DPPH radical scavenging ability, the metabolites from co-culturing CUR and the bacterium DCMB-002 showed moderate activity. The results implied that CUR may execute the bioactivities by both parent molecules and its biotransformation/ auto-degradation products, while in the aqueous environment the later ones may play major roles regarding as low water solubility of CUR. The biotransformation study herein helps to interpret the CUR performance in gut tracts and the roles of single gut bacterium in converting CUR, and provides an avenue to biosynthesizing active CUR analogues in vitro. Except for enriching new chemical entities, the biotransformation effects of the bacterium is also meaningful for improving the bioavailability of CUR by increasing hydrophilic ability of its products (as shown in HPLC profiles), which is related to the coculturing period of CUR and the bacterium, together with the characteristics of the bacterial life cycle. The auto-degradation of CUR in cultural medium and digestive tracts seems inevitable, whose proceeding may be influenced by various enzymes of gut flora, but the detailed effects and mechanism remain to be explored.

To summarize, the gut bacteria $B$. megaterium DCMB-002 can transform CUR to a variety of bioactive compounds. Our recent study revealed the regulative effect of CUR administration on gut microbiota in mice [31]. Thus, the interactions of CUR with gut microbiota seem bidirectional and deserve further investigations.

\section{Disclosure statement}

No potential conflict of interest was reported by the authors. 


\section{Funding}

This work has been supported by the National Natural Science Foundation of China [Grant No. 31370745 and 31600270] and Shandong Provincial Science Foundation for Distinguished Young Scholars [Grant No. JQ201508].

\section{References}

[1] Hussain Z, Thu HE, Amjad MW, et al. Exploring recent developments to improve antioxidant, anti-inflammatory and antimicrobial efficacy of curcumin: A review of new trends and future perspectives. Mater Sci Eng C Mater Biol Appl. 2017;77:1316-1326.

[2] Di Martino RM, Luppi B, Bisi A, et al. Recent progress on curcumin-based therapeutics: a patent review (2012-2016). Part I: curcumin. Expert Opin Ther Pat. 2017;27:579-590.

[3] Sharma RA, Gescher AJ, Steward WP. Curcumin: the story so far. Eur J Cancer. 2005;41:1955-1968.

[4] Anand P, Kunnumakkara AB, Newman RA, et al. Bioavailability of curcumin: problems and promises. Mol Pharm. 2007;4:807-818.

[5] Ji HF, Shen L. Can improving bioavailability improve the bioactivity of curcumin? Trends Pharmacol Sci. 2014;35:265-266.

[6] Yang KY, Lin LC, Tseng TY, et al. Oral bioavailability of curcumin in rat and the herbal analysis from Curcuma longa by LC-MS/MS. J Chromatogr B Analyt Technol Biomed Life Sci. 2007;853:183-189.

[7] Shen L, Ji HF. The pharmacology of curcumin: is it the degradation products? Trends Mol Med. 2012;18:138-144.

[8] Jankun J, Wyganowska-Swiatkowska M, Dettlaff K, et al. Determining whether curcumin degradation/condensation is actually bioactivation (Review). Int J Mol Med. 2016;37:1151-1158.

[9] Zeng Y, Qiu F, Liu Y, et al. Isolation and identification of phase I metabolites of demethoxycurcumin in rats. Drug Metab Dispos. 2007;35:1564-1573.

[10] Hoehle SI, Pfeiffer E, Sólyom AM, et al. Metabolism of curcuminoids in tissue slices and subcellular fractions from rat liver. J Agric Food Chem. 2006;54:756-764.

[11] Ireson C, Orr S, Jones DJL, et al. Characterization of metabolites of the chemopreventive agent curcumin in human and rat hepatocytes and in the rat in vivo, and evaluation of their ability to inhibit phorbol esterinduced prostaglandin E2 production. Cancer Res. 2001;61:1058-1064.

[12] Ramalingam P, Ko YT. A validated LC-MS/MS method for quantitative analysis of curcumin in mouse plasma and brain tissue and its application in pharmacokinetic and brain distribution studies. J Chromatogr B Analyt Technol Biomed Life Sci. 2014;969:101-108.

[13] Tan S, Calani L, Bresciani L, et al. The degradation of curcuminoids in a human faecal fermentation model. Int J Food Sci Nutr. 2015;66:790-796.

[14] Burapan S, Kim M, Han J. Curcuminoid demethylation as an alternative metabolism by human intestinal microbiota. J Agric Food Chem. 2017;65:3305-3310.

[15] Tan S, Rupasinghe TW, Tull DL, et al. Degradation of curcuminoids by in vitro pure culture fermentation. J Agric Food Chem. 2014;62:11005-11015.
[16] Zhang W, Huang J, Wo X, et al. Microbial transformation of curcumin to its derivatives with a novel Pichia kudriavzevii ZJPH0802 strain. Appl Biochem Biotechnol. 2013;170:1026-1037.

[17] Zhang X, Ye M, Li R, et al. Microbial transformation of curcumin by Rhizopus chinensis. Biocatal Biotransform. 2010;28:380-386.

[18] Dowd SE, Callaway TR, Wolcott RD, et al. Evaluation of the bacterial diversity in the feces of cattle using $16 \mathrm{~S}$ rDNA bacterial tag-encoded FLX amplicon pyrosequencing (bTEFAP). BMC Microbiol. 2008;8:125-132.

[19] Duan X-J, Zhang W-W, Li X-M, et al. Evaluation of antioxidant property of extract and fractions obtained from a red alga, Polysiphonia urceolata. Food Chem. 2006;95:37-43.

[20] Chiou Y-S, Wu J-C, Huang Q, et al. Metabolic and colonic microbiota transformation may enhance the bioactivities of dietary polyphenols. J Funct Foods. 2014;7:3-25.

[21] Asai A, Miyazawa T. Occurrence of orally administered curcuminoid as glucuronide and glucuronide/sulfate conjugates in rat plasma. Life Sci. 2000;67:2785-2793.

[22] Pan MH, Huang TM, Lin JK. Biotransformation of curcumin reduction and glucuronidation in mice. Drug Meta Disp. 1999;27:486-494.

[23] Lou Y, Zheng J, Hu H, et al. Application of ultraperformance liquid chromatography coupled with quadrupole time-of-flight mass spectrometry to identify curcumin metabolites produced by human intestinal bacteria. J Chromatogr B Analyt Technol Biomed Life Sci. 2015;985:38-47.

[24] Chen W, Fan-Havard P, Yee LD, et al. A liquid chromatography-tandem mass spectrometric method for quantification of curcumin-O-glucuronide and curcumin in human plasma. J Chromatogr B. 2012;900:89-93.

[25] Zhou Y, Liu K, Zhang J, et al. $\mathrm{Mg}^{2+}$-induced stabilization of beta-galactosidase from Bacillus megaterium and its application in the galactosylation of natural products. Biotechnol Lett. 2017;39:1175-1181.

[26] Zhang C, Xu SH, Ma BL, et al. New derivatives of ursolic acid through the biotransformation by Bacillus megaterium CGMCC 1.1741 as inhibitors on nitric oxide production. Bioorg Med Chem Lett. 2017;27:2575-2578.

[27] Yang S, Yan Q, Bao Q, et al. Expression and biochemical characterization of a novel type I pullulanase from Bacillus megaterium. Biotechnol Lett. 2017;39:397-405.

[28] Rolewicz M, Rusek P, Borowik K. Obtaining of granular fertilizers based on ashes from combustion of waste residues and ground bones using phosphorous solubilization by bacteria Bacillus megaterium. J Environ Manage. 2017. [Epub ahead of print]. DOI:10.1016/j. jenvman.2017.05.004

[29] Kumar D, Dubey KK. An efficient process for the transformation of betulin to betulinic acid by a strain of Bacillus megaterium. 3 Biotech. 2017;7:157-167.

[30] Luo L, Zhao Z, Huang X, et al. Isolation, identification, and optimization of culture conditions of a bioflocculant-producing bacterium Bacillus megaterium SP1 and its application in aquaculture wastewater treatment. Biomed Res Int. 2016;2016:2758168.

[31] Shen L, Liu L, Ji H-F. Regulative effects of curcumin spice administration on gut microbiota and its pharmacological implications. Food Nutr Res. 2017;61:1361780. 